Received: 22.10 .2019

Revised: 21.11 .2019

Accepted: 20.12 .2019

DOI: $10.17804 / 2410-9908.2019 .6 .087-101$

\title{
THE UMD-101MK FLAW DETECTION EQUIPMENT FOR AUTOMATED MAGNETIC INSPECTION OF ELECTRICALLY WELDED SMALL AND MEDIUM PIPES OVER THE ENTIRE WALL THICKNESS AND PERIMETER
}

\author{
A. S. Shleenkov ${ }^{\text {a)* }}$, O. A. Bulychev ${ }^{\text {b) }}$, S. A. Shleenkov ${ }^{\text {c) }}$, D. V. Novgorodov ${ }^{\text {d)** }}$ \\ M. N. Miheev Institute of Metal Physics, Ural Branch of the Russian Academy of Sciences, \\ 18 S. Kovalevskoy St., Ekaterinburg, 620108, Russian Federation \\ a) (iD https://orcid.org/0000-0002-6135-1504 \$ shleenkov@imp.uran.ru; \\ b) iD https://orcid.org/0000-0001-5412-3733 bulychev@imp.uran.ru; \\ c) iD https://orcid.org/0000-0002-2410-3202 s.shleenkov@imp.uran.ru; \\ d) iD https://orcid.org/0000-0002-5151-8710 @ novgorodov@imp.uran.ru \\ *Corresponding author. E-mail: shleenkov@imp.uran.ru; danil_@inbox.ru \\ Address for correspondence: 34 Komsomolskaya St., 620049, Ekaterinburg, Russian Federation
}

In this paper, a multichannel magnetoresistive signal measurement and processing system for a magnetic flaw detector is developed and investigated. On this basis, a new compact flaw detection complex is created and implemented in industry for automated continuous magnetic monitoring and identification of defects in small- and medium-diameter electrowelded pipes during production over the entire wall thickness, i.e. the entire volume. The optimal structural scheme and the distinctive features of the new automated device meeting modern requirements are considered. It is shown that the use of computer technology and high-resolution thin-film matrix transducers produced according to the advanced technology of manufacturing AMRD sensors significantly increases the functionality of the flaw detector and provides detection of not only metal discontinuities and edge shifts, but also defects caused by the violation of welding conditions, e.g. cracks, fistulas, burns or adhesion of edges in the weld area. The system based on single-chip thin-film matrix transducers of the new generation is highly sensitive and makes it possible to detect both surface and bulk defects in a contactless manner with a large gap and high speed.

Keywords: electrically welded pipes, magnetic inspection, combined magnetization system, thinfilm matrix magnetic transducers, surface and volume defects, non-contact scanning, rejection.

\section{Acknowledgment}

The work was performed under the state assignment from FASO Russia, theme Diagnostics No. AAAA-A18-118020690196-3.

\section{References}

1. Pashkov Yu.I. Problemy prochnosti, razrusheniya i resursa trub i truboprovodov. Tematicheskiy sbornik nauchnykh trudov OAO «RosNITI» [Thematic Collection of Papers of RosNITI OJSC]. Chelyabinsk, 2001, pp. 58-79. (In Russian).

2. Fedosenko Yu.K. Electromagnetic automated flaw detection inspection of pipes of a wide range of diameters and steel grades. Kontrol'. Diagnostika, 2001, no. 5, pp. 25-28. (In Russian).

3. Available at: www.kropus.com (accessed 28.12.2019). 
4. Shleenkov A.S., Bulychev O.A., Shleenkov S.A. The UMD-101M plant for automated bulk magnetic nondestructive testing of quality of electric-welded pipes. Russian Journal of Nondestructive Testing, 2008, vol. 44, pp. 574-578.DOI: 10.1134/S106183090808010X.

5. Bulychev O.A., Shleenkov S.A., Seniv V.M., Shleenkov A.S., Polezhaev L.A. The UMD104M device for testing reusable oil-well tubing. Russian Journal of Nondestructive Testing, 2015, vol. 51, pp. 661-668. DOI: 10.1134/S1061830915110029.

6. Available at: www.mac-ndt.com

7. Available at: www.foerster.ru

8. $\quad$ Available at: www.nov.com/tuboscope (accessed 28.12.2019).

9. Available at: www.GEInspectionTechnologies.com (accessed 28.12.2019).

10. Bulychev O.A. Magnetoresistive converter to read information from magnetic carriers, RF Patent 2175455, 2001. (In Russian).

11. Bulychev O.A., Shleenkov A.S. Two-component matrix converter of magnetic field, RF Patent 2290654, 2006. (In Russian).

12. Shleenkov A.S. Development of array transducers of magnetic field with regard to nondestructive check of ferromagnetic articles and welded joints. Doctoral (Tech.) Dissertation, IFM UrO RAN, Ekaterinburg, 1998. (In Russian).

13. Shleenkov A.S., Bulychev O.A., Lyadova N.M., Shcherbinin V.E., and Bychkov V.G. Estimating the possibility of the magnetic detection of microflaws in weld seams of longitudinal electric-welded pipes manufactured by butt high-frequency welding. Russ. J. Nondestr. Test., 2010, vol. 46, no. 2, pp. 92-97. DOI: 10.1134/S1061830910020038.

14. Bulychev O.A., Shleenkov S.A., Shleenkov A.S. Multichannel magnetoresistive magnetic inspection system for seamless thick-walled pipes. Defektoskopiya, 2018, no. 10, pp 58-63. Available at: http://defectoskopiya.ru/index (accessed 28.12.2019). (In Russian). 
Подана в журнал: 22.10.2019

УДК 620.179.14

DOI: $10.17804 / 2410-9908.2019 .6 .087-101$

\title{
ДЕФЕКТОСКОПИЧЕСКИЙ КОМПЛЕКС УМД-101МК ДЛЯ АВТОМАТИЗИРОВАННОГО МАГНИТНОГО КОНТРОЛЯ ЭЛЕКТРОСВАРНЫХ ТРУБ МАЛОГО И СРЕДНЕГО ДИАМЕТРОВ ПО ВСЕМУ ПЕРИМЕТРУ И ВСЕЙ ТОЛЩИНЕ СТЕНКИ
}

\author{
А. С. Шлеенков ${ }^{\text {a) }}$, О. А. Булычев ${ }^{\text {() }}$, С. А. Шлеенков ${ }^{\text {в) }}$, Д. В. Новгородов ${ }^{\text {г) }}$ \\ Институт физики металлов имени М.Н. Михеева Уральского отделения Российской академии наук, \\ ул. С. Ковалевской 18, Екатеринбург, 620108, Российская Федерация \\ a) (D) https://orcid.org/0000-0002-6135-1504 《 shleenkov@imp.uran.ru; \\ б) (iD https://orcid.org/0000-0001-5412-3733 bulychev@imp.uran.ru; \\ в) (DD https://orcid.org/0000-0002-2410-3202 @ s.shleenkov@imp.uran.ru; \\ г) (D) https://orcid.org/0000-0002-5151-8710 @ novgorodov@imp.uran.ru
}

\begin{abstract}
"Ответственный автор. Электронная почта: shleenkov@imp.uran.ru; danil_@inbox.ru
Адрес для переписки: ул. Комсомольская, 34, г. Екатеринбург, 620049, Российская Федерация
\end{abstract}

В работе разработана и исследована многоканальная магниторезистивная система измерения полей дефектов и обработки результатов неразрушающего контроля магнитным методом (методом рассеяния магнитного потока MFL), на основе которой создан и внедрен в промышленности новый малогабаритный дефектоскопический комплекс для автоматизированного непрерывного магнитного контроля и идентификации дефектов электросварных труб малого и среднего диаметра в процессе их производства по всей толщине стенки, т. е. по всему объему. Рассмотрены оптимальная структурная схема и отличительные особенности новой автоматизированной установки, отвечающей современным требованиям. Показано, что применение компьютерных технологий и тонкопленочных матричных преобразователей высокого разрешения, полученных с применением передовой технологии изготовления анизотропных магниторезистивных датчиков (АМРД), позволяет существенно увеличить функциональные возможности дефектоскопа и обеспечивает выявление не только дефектов типа нарушений сплошности металла и смещений кромок, но и дефектов, обусловленных нарушением режимов сварки типа трещин, свищей, прижогов и слипаний кромок в области сварного шва. Система на основе однокристальных тонкопленочных матричных преобразователей нового поколения обладает высокой чувствительностью и позволяет выявлять как поверхностные, так и объемные дефекты бесконтактным способом с большим зазором и с высокой скоростью.

Ключевые слова: электросварные трубы, магнитный контроль, комбинированная система намагничивания, тонкопленочные матричные магнитные сенсоры, поверхностные и объемные дефекты, бесконтактное сканирование, отбраковка.

\section{1. Введение}

На современном этапе производства сварных труб из углеродистых и низкоуглеродистых сталей, свариваемых контактной и дуговой сваркой, предъявляются повышенные требования к качеству и обеспечению гарантированной надежности и безопасности при эксплуатации. В основной массе сварные трубы используются для сооружения трубопроводных систем для транспортировки различных углеводородных продуктов (газ, нефть, нефтепродукты и др.) [1]. Трубопроводы эксплуатируются при очень высоких рабочих параметрах: 
рабочее давление до $25 \mathrm{MПа,} \mathrm{температура} \mathrm{до}-60{ }^{\circ} \mathrm{C}$, статические и циклические нагрузки и являются потенциально опасными объектами. Особые требования к качеству сварных труб обусловлены также соответствующими требованиями к применяемым методам неразрушающего контроля (НК), которые на современном этапе являются одним из технических звеньев повышения эксплуатационной надежности трубной продукции. Поэтому проблема надежного контроля качества сварного соединения и самих труб является актуальной.

Средства неразрушающего контроля (НК) как и средства гидроиспытаний стальных труб, относятся к испытательному оборудованию и решают одну и ту же задачу - повышение качества трубной продукции. Обычно их применяют совместно, однако в ряде случаев допускается замена гидроиспытаний на 100 \% НК. Это обусловлено прежде всего тем, что тонкие дефекты, выявляемые современными высокочувствительными методами НК, гидроиспытаниями не подтверждаются, хотя в результате металлографических исследований эти дефекты, как правило, обнаруживаются. Причина этого понятна. По данным [1], при гидроиспытаниях труб с тонкими дефектами (продольные трещины, несквозные непровары и т. д.), глубина которых составляет до 70 \% толщины стенки, последние ничем себя не проявляют даже при испытательном давлении, в несколько раз превышающем норму.

Чтобы гарантировать высокое качество трубной продукции необходимо быть уверенным, что применяемые средства НК отвечают современным требованиям, в том числе установленным в ГОСТ 31447 и ГОСТ 20295, а также в стандартах ISO 10893-3:2011 и ASTM (Е 570-91). В работе разработана и исследована многоканальная магниторезистивная система измерения и обработки сигнала для магнитного дефектоскопа на основе которой создан и внедрен в промышленности новый малогабаритный дефектоскопический комплекс для автоматизированного магнитного контроля электросварных труб малого и среднего диаметра по всей толщине стенки, т. е. по всему объему.

\section{2. Постановка задачи}

Проведен анализ работы существующих дефектоскопов, применяемых для объемношовной дефектоскопии электросварных труб диаметром $(20 \div 114)$ мм, изготавливаемых продольно-стыковой сваркой давлением.

Если НК ведется на непрерывной трубе, то чаще всего применяются вихретоковые $[2,3]$ и магнитные дефектоскопы [4-8] (УЗК для решения этой задачи применяется, как правило, только в дорогостоящих импортных установках ротационного типа).

Известно, что наиболее опасные дефекты электросварных труб, изготавливаемых высокочастотной сваркой давлением, имеют продольную ориентацию (вдоль оси трубы). Считается, что указанные дефекты хорошо выявляются вихретоковыми дефектоскопами на проходных катушках при условии, что глубина их залегания не превышает 5 мм. Это достигается применением продольного постоянного подмагничивающего поля. Наблюдается увеличение чувствительности дефектоскопа к поперечным трещинам или объемным дефектам типа: прожог, сплошной непровар, закат, неметаллические включения и т. д. Внутренние продольно ориентированные дефекты при этом выявляются не всегда. Кроме того известно, что применительно к НК стальных труб вихретоковые дефектоскопы на проходных катушках по чувствительности существенно уступают магнитным. Особенно это становится заметным с увеличением диаметра контролируемых труб. Это подтверждают результаты сравнительных испытаний магнитного и вихретокового дефектоскопов на одном из трубных заводов [13].

Поскольку применение акустических методов [9] для НК электросварных труб, изготовленных стыковой высокочастотной сваркой, с неснятым внутренним гратом также малоэффективно, возникла необходимость создания установки для неразрушающего контроля всего тела электросварных труб малого и среднего диаметра. 
Следует подчеркнуть, что полная замена гидроиспытаний допустима в случае, если применяемые средства НК обеспечивают выявление недопустимых дефектов по всей толщине стенки трубы, т. е. по всему объему. В этом плане магнитный метод НК весьма перспективен. В настоящее время существуют достаточно недорогие магнитные дефектоскопы, успешно используемые в трубной промышленности.

Речь, прежде всего, идет об установках УМД-101М [4], предназначенных для объемно-шовной дефектоскопии прямошовных электросварных труб, выпускаемых по ГОСТ 31447, ГОСТ 10705, ГОСТ 20295, ГОСТ 10707, ГОСТ 3262 в технологическом потоке их производства, вблизи трубоэлектросварочного агрегата там, где труба еще непрерывна (НК идет без вращения трубы), а также об установках УМД-104М [7] для магнитной дефектоскопии труб нефтяного сортамента, выпускаемых по ГОСТ 633-80, ГОСТ 632-80, ASTM(E 570-91), API5CT, API5L и др.

Эти установки созданы в Институте физики металлов УрО РАН, в их основе - однокристальные тонкопленочные матричные преобразователи (МП) магнитного поля, изготовленные с применением современных нанотехнологий $[10,11]$. В качестве магниточувствительных элементов (МЧЭ) в них использованы тонкопленочные (толщина пленки 20 нм) магниторезистивные датчики (АМРД), реализующие предложенный новый принцип измерения напряженности магнитных полей дефектов [12].

Отличительная особенность АМРД состоит в их чрезвычайно высокой чувствительности НК, поэтому ведется с рабочим зазором $(3 \div 7)$ мм, что существенно повышает надежность первичных преобразователей.

Синтез МП с применением современных интегральных технологий позволяет выпускать их в больших количествах, в результате чего появилась возможность организовать НК электросварных и горячекатаных труб по всему объему. Это достигается равномерным размещением МЭ по периметру трубы, которая поступательно перемещается со скоростью до 2 м/с относительно неподвижных МЭ.

Несмотря на то, что вышеперечисленные установки магнитного НК $[4,7]$ нашли широкое промышленное применение, они морально устарели, имеют существенные недостатки и нуждаются в модернизации. Особенно в части конструкции, габаритных размеров, программного и метрологического обеспечения, повышения чувствительности и улучшения эксплуатационных характеристик. Необходимо также расширить рабочий и температурный диапазоны работы датчиков.

\section{3. Устройство и возможности малогабаритного дефектоскопического комплекса}

Поставленная цель достигнута за счет применения, разработанных и синтезированных в ИФМ УрО РАН новых однокристальных тонкопленочных матричных преобразователей на основе анизотропных магниторезистивных датчиков (АМРД) повышенной чувствительностью к продольно ориентированным дефектам, передовой технологии изготовления датчиков АМРД, предусматривающей высокотемпературный отжиг (до $1200{ }^{\circ} \mathrm{C}$ ) пермаллоевых пленок на окончательной стадии изготовления магниторезистивных датчиков, разработке более информативного ПО, разработке устройств стабилизации трубы и более надежной механики, а также современного дизайна установки.

Очевидно, что при столь значительной температурной обработке изменяются структурные характеристики пленки, что приводит к изменению основных структурночувствительных магнитных параметров: величины магниторезистивного эффекта (возможен его прирост на 50 \%), коэрцитивной силы, начальной восприимчивости и постоянной магнитострикции.

Кроме этого, благодаря компьютерному моделированию магнитной системы, удалось существенно уменьшить габариты установки в направлении движения трубы (длина уста- 
новки вдоль ее оси не более 700 мм), что впервые позволило разместить совмещенный измерительный модуль (магнитный сканер) контрольной позиции дефектоскопического комплекса с системами «верх-низ $180^{\circ}$ », предназначенный одновременно для выявления как продольно-ориентированных, так и объемных дефектов в сварном шве и теле электросварных труб по всему периметру и всей толщине стенки (с охватом $360^{\circ}$ ) на общей стационарной платформе между калибровочными клетями.

В результате исследований на основе применения МП нового поколения создан новый высокоэффективный малогабаритный дефектоскопический комплекс УМД-101МК для магнитного контроля электросварных труб малого и среднего диаметра по всему периметру. Внешний вид дефектоскопического комплекса УМД-104МК представлен на рис. 1. (фотография снята на стане ТЭСА 20-114 ОАО «Магнитогорский металлургический комбинат»).
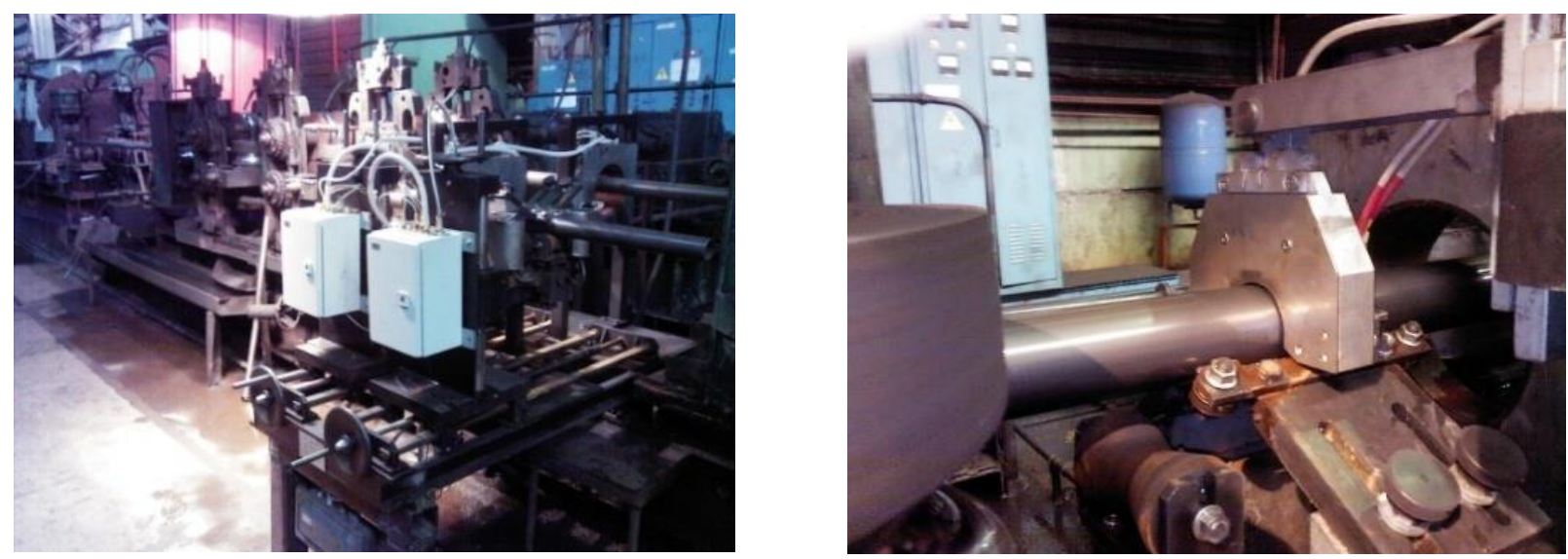

Рис. 1. Дефектоскопический комплекс УМД-101МК

Комплекс предназначен для испытаний стальных прямошовных электросварных труб диаметром от 20 до 114 мм, изготовленных по ГОСТ 31447, ГОСТ 10705, ГОСТ 20295, ГОСТ 3262, API 5L, API 5CT и DIN EN 10208 и техническим условиям, в технологическом потоке их производства, вблизи трубоэлектросварочного агрегата там, где труба еще непрерывна (то есть НК идет без вращения трубы) на наличие дефектов типа нарушений сплошности сварного шва и тела (по всему объему, включая верхнюю и нижнюю половины трубы в пределах $360^{\circ}$ ). Контролю могут подвергаться трубы только со снятым наружным гратом. Наличие внутреннего грата не отражается на результатах контроля. Температура сварного шва в зоне контроля не должна превышать $100{ }^{\circ} \mathrm{C}$.

Конструкция установки позволяет проводить полностью автоматизированный неразрушающий контроль (НК) сварного шва, околошовной зоны и тела стальных электросварных прямошовных труб на наличие дефектов типа нарушений сплошности, выводящих толщину стенки трубы за пределы, предусмотренные промышленными нормами стандарта ASTM (Е570-91) и др.

В современной комплектации дефектоскопический комплекс УМД-101МК может быть использован для магнитного контроля электросварных труб диаметром 2-114 мм, толщиной стенки до 8 мм (возможно расширение диапазона диаметров до 219 мм и толщины стенки до 16 мм) в процессе их изготовления. Магнитный дефектоскоп УМД-101МК используется, как правило, в технологическом потоке на непрерывной трубе. С небольшими изменениями (в механике) он может применяться для входного (выходного) контроля мерных труб.

Комплекс обеспечивает выявление дефектов, выходящих на наружную и внутреннюю поверхности, а также по всей толщине сварного шва околошовной зоны и тела трубы. 
Дефектоскоп обеспечивает контроль тела и сварного шва трубы согласно требованиям стандартов ISO 10893-3:2011 и ASTM (E570-91) с чувствительностью, установленной по выявлению сквозного отверстия диаметром 1,6 мм и/или расположенного на наружной и внутренней поверхностях трубы продольного искусственного дефекта (риски) прямоугольного профиля со следующими параметрами:

- длина не менее, мм

25

- ширина, мм

- глубина, \% (от номинальной толщины стенки трубы) 10

Комплекс также обеспечивает обнаружение магнитным методом (рассеяния магнитного потока MFL) в теле трубы сквозных отверстий и свищей диаметром более 0,79 мм.

Настройка чувствительности аппаратуры контроля производится по продольным, поперечным и наклонным прямоугольным пазам N5 на наружной и внутренней поверхностях трубы, выполненным по ASTM (E570-91) и др.

\section{Базовый состав комплекса}

1. Система УМД-101МКП 20-114 - контрольная позиция (КП) для магнитной дефектоскопии (МД) продольного сварного шва и всего тела электросварных прямошовных труб круглого сечения в технологическом потоке их производства на непрерывной трубе в линии ТЭСА 20-114 при их поступательном, продольном перемещении в технологической линии неразрушающего контроля (НК).

2. Система УМД СО 114 обработки и индикации результатов магнитной дефектоскопии.

3. Управляющий вычислительный комплекс (УВК) с оборудованием автоматики.

4. Платформа для стационарного размещения контрольной позиций в зоне НК.

\section{Вспомогательное оборудование}

Калибровочная станция:

- обеспечивает управление и перемещения контрольного образца (далее по тексту СОП) из позиции контроля в позицию калибровки и обратно;

- позволяет выполнять калибровку оборудования в динамическом диапазоне.

\section{Оборудование автоматики в составе}

1. Местный пульт дистанционного управления (ПДУ) с сенсорным терминалом и возможностью переключения управления на главный и местный пульты.

2. Главный пульт управления, находящийся в помещении существующего главного пульта ТЭСА со световой и звуковой сигнализацией, показывающий положение и состояние исполнительных механизмов.

3. Шкаф автоматики с кабельными линиями управления и электропитания.

4. Контроллер системы автоматики с программным обеспечением.

5. Электронный блок управления механизмами перемещения.

6. Шкаф электропитания.

7. Система маркировки дефектов, состоящая из блока дефектоотметчика и краскоотметчиков.

\section{Комплектация (стандартная)}

Конструктивно дефектоскоп представляет собой две самостоятельные системы (дефектоскопический комплекс «верх-низ $\left.180^{\circ} »\right)$ : одна служит для магнитной дефектоскопии 
верхней части трубы, вторая - нижней. Различие в выполняемых функциях обусловливает различие в конструкциях механических систем.

В состав контрольной позиции (КП) УМД-101М КП 20-114 входит совмещенный измерительный модуль (магнитный сканер), предназначенный одновременно для выявления как продольно ориентированных, так и объемных дефектов в сварном шве и теле электросварных труб по всему периметру и всей толщине стенки (с охватом $360^{\circ}$ ).

Измерительный модуль содержит:

- намагничивающее устройство (НУ), состоящее из двух электромагнитов постоянного тока для поперечного намагничивания труб и двух катушек продольного намагничивания;

- две измерительные самоцентрирующиеся кассеты на каждый типоразмер (диаметр) контролируемых труб с магниточувствительными элементами-датчиками АМРД с прижимным устройством типа пантограф, снабженные тонкостенным металлическим кожухом для водяного охлаждения днища кассеты;

- систему водопитания с фильтром и отстойником;

- комплект магниточувствительных элементов - тонкопленочных магниторезистивных АМРД датчиков (матричных преобразователей) $\mathrm{H}_{\tau}$ типа (осуществляют измерение тангенциальной составляющей магнитного поля рассеяния в области дефекта), предназначенных для обнаружения продольных и объемных несовершенств. МП размещены в шахматном порядке в специальных кассетах, обеспечивающих однородность зазора датчик - поверхность контролируемой трубы и защиту МЭ от механических повреждений, попадания грязи, влаги, масел и т. д;

- комплект магниточувствительных элементов - тонкопленочных магниторезистивных АМРД датчиков (матричных преобразователей) $\mathrm{H}_{\mathrm{n}}$ типа (осуществляют измерение нормальной составляющей магнитного поля рассеяния в области дефекта), предназначенных для обнаружения поперечных и объемных несовершенств;

- устройство обеспечения постоянства зазора датчик-труба;

- механизм (устройство) подвода-отвода (доставки) полюсов НУ и кассеты с датчиками к трубе;

- пневматическую систему, предназначенную для управления устройствами подводаотвода полюсов НУ и кассеты с датчиками к трубе;

- механизм перемещения измерительного модуля (НУ и кассет с тонкопленочными АМРД преобразователями с устройством обеспечения постоянства зазора датчик-труба, а также устройством доставки полюсов НУ и кассеты с датчиками к трубе) из позиции контроля в позицию калибровки и обратно;

- блок дефектоотметчика и автоматическую систему маркировки дефектных участков

Система обработки и индикации результатов измерений включает:

- оборудование дефектоскопической электроники, предназначенное для приема сигналов от МЧЭ, размещенных вблизи объекта контроля, предварительного их усиления и передачу в УВК. Оборудование включает шкафы с блоками электроники, выносные предварительные усилители;

- приборные шкафы на контрольной позиции.

В приборном шкафу контрольной позиции находятся:

- блок обработки данных с системой терморегуляции, предназначенный для коммутации МЧЭ в измерительных кассетах, а также первичной обработки поступающей информации и «поканальной» калибровки МЧЭ с целью достижения их одинаковой чувствительности;

- промышленная станция типа IPC-510-SYS 2-1 с источником бесперебойного питания; 
- интерфейс для выработки и передачи цифрового сигнала о наличии дефекта на центральный промышленный компьютер, находящийся в помещении существующего главного пульта ТЭСА;

- плоскопанельный ТFТ-монитор;

- блоки питания НУ.

Платформа для стационарного размещения КП в зоне НК представляет собой механическую конструкцию, в состав которой входят:

- стальная плита с приспособлениями для крепления контрольной позиции УМД101М КП 20-114 со сменными деталями (узлами), меняющимися в зависимости от требуемых типоразмеров труб;

- механическая система для регулировки платформы по высоте;

- пневматический или электрический привод.

Основные параметры комплекса УМД-101МК приведены в таблице.

Технические характеристики

\begin{tabular}{|c|c|}
\hline Наименование параметра & Значение \\
\hline 1. Диаметр контролируемых труб, мм & $20 \div 114$ \\
\hline 2. Толщина стенки труб, мм & $2,5 \div 8$ \\
\hline 3. Скорость движения труб, м/мин & $9 \div 60$ \\
\hline 4. Температура сварного шва, ${ }^{\circ} \mathrm{C}$ & до 100 \\
\hline $\begin{array}{l}\text { 5. Наибольшее отклонение оси трубы от оси линии контроля } \\
\text { при движении трубы через дефектоскоп, мм }\end{array}$ & \pm 5 \\
\hline 6. Овальность, \% & \pm 5 \\
\hline $\begin{array}{l}\text { 7. Чувствительность дефектоскопа } \\
\text { Параметры выявляемых искусственных дефектов: } \\
\text { - длина, мм } \\
\text { - глубина поверхностного дефекта (риски) от номинальной } \\
\text { толщины стенки трубы, \% } \\
\text { - ширина дефекта, мм } \\
\text {-диаметр отверстия, мм }\end{array}$ & $\begin{array}{c}10 \ldots .50 \\
10 \pm 1,5, \text { но не } \\
\text { менее } 0,3 \pm 0,05 \\
0,5^{+0,05} \\
1,6\end{array}$ \\
\hline $\begin{array}{l}\text { 8. Рабочий зазор между днищем измерительной кассеты } \\
\text { с датчиками и трубой, мм }\end{array}$ & $3 \div 7$ \\
\hline $\begin{array}{l}\text { 9. Габаритные размеры, мм } \\
\left.\text { - контрольная позиция установки («верх } 180^{\circ} » \text { и «низ } 180^{\circ} »\right) \\
\text { - шкаф приборный }\end{array}$ & $\begin{array}{l}700 \times 1000 \times 1400 \\
800 \times 600 \times 2000\end{array}$ \\
\hline
\end{tabular}

Отличительные особенности дефектоскопического комплекса УМД-101МК:

- комплекс при необходимости (высоких скоростях движения трубы) может включать в себя измерительную самоцентрирующуюся кассету на каждый типоразмер (диаметр) контролируемых труб с магниточувствительными элементами-датчиками типа АРМД и прижимным устройством типа пантограф, снабженную тонкостенным металлическим кожухом для водяного охлаждения днища кассеты, а также систему водопитания с фильтром и отстойником (эта технология опробована в лабораторных условиях);

- возможность контроля труб без их вращения;

- возможность контроля нефтегазопроводных труб по всему периметру (и всей толщине стенки) в соответствии с требованиями ГОСТ 31447 и ГОСТ 20295; 
- впервые применена передовая технология изготовления датчиков АМРД, предусматривающая высокотемпературный отжиг (до $1200{ }^{\circ} \mathrm{C}$ ) пермаллоевых пленок на окончательной стадии изготовления магниторезистивных датчиков;

- благодаря высокой чувствительности МЭ нового поколения контроль ведется с рабочим зазором $3 \div 7$ мм, что существенно повышает надежность первичных преобразователей по сравнению с известными магнитными дефектоскопами $[5,6]$, где максимальный зазор составляет $1,5 \mathrm{mm;}$

- возможность выявления как продольных, так и поперечных или ориентированных под углом к оси трубу наклонных дефектов;

- возможность выявления дефектов, обусловленных нарушением режимов сварки типа трещин, свищей, прижогов и слипаний кромок, а также их смещений в области сварного шва;

- контроль проводится в автоматическом режиме с представлением информации на экране монитора промышленной станции.

\section{Устройство и работа составных частей установки}

Контрольная позиция (модель УМД-101М КП 20-114) установки предназначена для выполнения следующих функций:

- проведения контрольных операций на электросварных трубах диаметром от 20 до 114 мм;

- настройки установки на СОП;

- доставки первичных преобразователей в зону контроля и их защиты от механических повреждений;

- ручной переналадки при переходе от одного диаметра к другому.

Система обработки и индикации результатов магнитной дефектоскопии установки УМД-101МК состоит из измерительных кассет с первичными преобразователями, компьютерной системы, блоков коммутации и автоматики с соединительными кабелями, а также блока питания датчиков, блока дефектоотметчика с краскоотметчиком. Каждая кассета содержит от 8 до 32 магниточувствительных датчиков. Компьютерная система представляет собой промышленную станцию технологического управления Advantix SYS, встроеную в шкаф электрооборудования.

Оптимальный рабочий зазор между днищем кассеты и поверхностью контролируемой трубы составляет $3 \div 7$ мм.

Управляющий вычислительный комплекс, находящийся в помещении существующего главного пульта, ТЭСА включает:

- шкаф с интегрированными блоками цифровой обработки сигналов;

- промышленный компьютер (промышленная станция) типа IPC-510-SYS1 с источником бесперебойного питания (UPS) с двойным преобразованием (on-line), предназначенный для управления работой дефектоскопа и хранения данных, поступающих с контрольной позиции;

- современный интерфейс;

- плоскопанельный ТFT-монитор.

Блок коммутации и управления БК-3М предназначен для предварительного усиления, аналого-цифрового преобразования сигналов с первичных преобразователей и передачи информации через интерфейс USB на станцию технологического управления Advantix SYS модели IPC-510-SYS2-1. Он состоит из платы предварительных усилителей и модуля АЦП E14-440. Блок соединен через кабель USB со станцией технологического управления. По кабелю передаются сигналы управления блоком дефектоотметчика и сигналы с первичных преобразователей. 
Блоки коммутации БК-3М с измерительными кассетами расположены непосредственно на механической части установки, а блоки обработки данных и дефектоотметчика укреплены внутри шкафа электрооборудования. К шкафу электрооборудования подводится кабель питания от промышленной сети 380 В, 50 Гц, кабели питания намагничивающих устройств. К блоку коммутации БК-3М подведен кабель питания и кабель USB, по которому осуществляется передача первичной информации о результатах контроля.

Магниточувствительные датчики, расположенные в кассетах, последовательно подключаются к блоку БК-3М, к коммутационному блоку одновременно может быть подключено 8 разъемов (32 датчика). Увеличение (уменьшение) числа датчиков в зависимости от диаметра кассеты (диаметра контролируемой трубы) производится простым присоединением (разъединением) разъемов от датчиков к коммутационному блоку БК-3М.

Каждая кассета содержит от 8 до 32 пазов (в зависимости от диаметра трубы), в которых размещаются магниточувствительные датчики. В результате образуется двухрядная система датчиков, расположеных в шахматном порядке. Это позволяет обеспечить полное перекрытие датчиками зоны контроля (системами «верх $180^{\circ} »$ и/или «низ 180»), которая инспектируется одной кассетой.

В случае применения горизонтально ориентированных датчиков применяются дополнительные НУ: подмагничивающие катушки ПС-1 - для создания поля смещения в рабочей зоне, где расположены преобразователи. Обмотка ПС-1 содержит 1000 витков диаметром

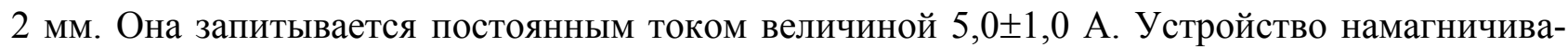
ющее (далее - НУ) служит для создания постоянного магнитного потока в теле контролируемой трубы.

Электромагнит состоит из магнитопровода, двух обмоток, включенных последовательно, полюсных наконечников (ПН), которые ориентированы под углом $120^{\circ}$ относительно друг друга и имеют возможность радиального перемещения для настройки на каждый типоразмер трубы. ПН снабжены защитными роликами, необходимыми для установки постоянного зазора (до 5 мм) между поверхностями трубы и полюсных наконечников.

Конструкция электромагнита разработана на основе данных компьютерного моделирования, что позволило обеспечить достаточную однородность намагничивающего поля в зоне НК, необходимую для создания одинаковых условий работы МЭ. Для выявления поперечно ориентированных дефектов установка снабжается дополнительным соленоидом, намагничивающим трубу вдоль ее образующей.

Все детали магнитопровода изготовлены из магнитомягкого материала - стали типа «Армко» (либо стали Ст3). Намагничивающее устройство (с кассетой и датчиками) подвешено на кронштейнах таким образом, чтобы обеспечивать адекватное перемещение магнитной системы при перемещении трубы «влево», «вправо» и «вверх» (для слежения за трубой при ее поперечных перемещениях в пределах до 10 мм).

Катушки электромагнита намотаны на металлические каркасы, и содержат каждая по 1000 витков медного изолированного провода диаметром 1,5 мм. Катушки соединены последовательно и запитываются постоянным током величиной $3,0 \div 5,0$ А от блока питания, входящего в состав электронной системы установки. Такие параметры НУ обеспечили требуемый уровень намагничивания. Напряженность тангенциальной составляющей магнитного поля в зоне НК трубы диаметром 114мм составила $30 \mathrm{~A} / \mathrm{cm}$.

Блок дефектоотметчика БД-1 предназначен для подачи напряжения на дефектоотметчик при прохождении дефекта под первичными преобразователями. Также в блоке формируется задержка пропорциональная расстоянию между дефектоотметчиком и первичными преобразователями. Задержка формируется с помощью микропроцессора Регулировка длительности задержки срабатывания дефектоотметчика производится с помощью подстроечного резистора. 
Блок питания датчиков предназначен для формирования стабилизированного напряжения 5 В, питающего предварительные усилители в БК-3М и регулируемого стабилизированного напряжения возбуждения первичных преобразователей 1...3 В.

Устройство доставки первичных преобразователей служит для центровки НУ, а также кассеты с датчиками относительно трубы или СОП. Оно представляет собой опорную плиту с направляющими, ползуном, винтом вертикального хода, траверсой. В случае системы «верх $180^{\circ}$ » к ползуну крепится кронштейн, на который навешивается НУ, а центровка кассет с датчиками производится с помощью подвески, которая крепится к траверсе.

В системе «низ $180^{\circ} »$ кассета с помощью шарнира устанавливается непосредственно на плите магнитопровода НУ кронштейна, который также крепится к ползуну.

В обеих системах предусмотрена защита от аварийных ситуаций, поскольку кассеты с датчиками прикреплены к шарниру, который обеспечивает откидывание кассеты под углом $45^{\circ}$ в направлении, обратном направлению движения трубы, при попадании в зону контроля шва с плохо снятым гратом, сплошным непроваром или наплывами металла.

Для защиты днища кассеты на ее боковых крышках установлены подшипники, обес-

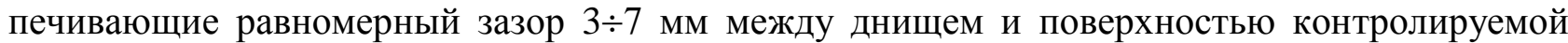
трубы. Кроме того, кронштейны систем «верх $180^{\circ}$ » и «низ $180^{\circ}$ » связаны с ползуном двумя вертикальными направляющими и центральным винтом с трапециидальной резьбой, заканчивающейся маховиком в случае системы «верх $180^{\circ}$ » или аналогичным маховиком системы «низ $180^{\circ}$ ». Такая конструкция обеспечивает быстрый отвод кассеты с первичными преобразователями из зоны контроля в случае возникновения аварийной ситуации.

Разработано также необходимое программное обеспечение, которое позволяет выполнять следующие функции:

- преобразование и обработка сигналов с каждого матричного преобразователя магнитного поля;

- передачу информационных сигналов от первичных блоков обработки, расположенных на контрольных позициях, на аппаратуру, размещенную возле рабочего места оператора;

- передачу всей информации в реальном масштабе времени;

- помехоустойчивость трансляции данных;

- оперативный контроль за нормальным состоянием системы магнитного контроля и каналов передачи данных;

- цифровую запись отображения дефектов (в том числе топографии их магнитного поля) контролируемой поверхности;

- компьютерную обработку отображений (определение характеристик дефектов и их местоположения);

- формирование массивов данных выявленных дефектов.

\section{Возможности комплекса в части автоматической разбраковки труб:}

- автоматическое разделение труб на годные и бракованные по наличию нарушений сплошности металла в теле трубы и сварных соединениях, выводящих остаточную толщину стенки трубы за пределы минимально указанного в НТД значения;

- определение границ дефектных участков с передачей данных на устройство автоматической маркировки и устройство.

Кроме этого, комплекс обеспечивает:

- оперативную диагностику электронного оборудования;

- визуальное изображение сигналов от несплошностей при настройке и в процессе работы установки;

- отображение информации о дефектных зонах, сопровождение их изображения на мониторах; 
- классификацию дефектов в соответствии с установленными оператором требованиями;

- выдачу сигналов на маркировку дефектных зон;

- резервное копирование информации и включение системы аварийного питания;

- архивирование и хранение данных;

- функционирование в дружественном, интуитивно-понятном интерфейсе.

\section{Возможности системы управления дефектоскопом и оборудования автоматики:}

- система управления объединяет, координирует и синхронизирует работу всех подсистем установки, осуществляет управление информационными потоками, организует процесс контроля, сбор, обработку, представление и хранение результатов, а также организует контроль в соответствии с установленными оператором правилами и нормами.

- оборудование автоматики обеспечивает реализацию основных режимов контроля, управление исполнительными механизмами установки, диагностику работоспособности узлов и механизмов установки, определение координат дефектов, индикацию состояния всех датчиков системы, маркировку дефектов, а также контроль нештатных и недопустимых ситуаций (осуществляется специальными ресурсами системы автоматики).

\section{4. Результаты метрологической аттестации и внедрения}

Комплекс внедрен в ОАО «Магнитогорский металлургический комбинат» в 2014 г. В том же году выполнена его метрологическая аттестация. Она проводилась в соответствии с ГОСТ Р 8.568 по методике, разработанной ФГУП «УНИИМ», г. Екатеринбург согласно требованиям ГОСТ Р 8.563-96. Особенностью методики является то, что кроме измерений на стандартных образцах в статике (с помощью калибровочной станции) проведены соответствующие измерения в динамике.

На рис. 2 представлены результаты измерений, полученные с помощью установки УМД-101М на трубе диаметром 26,8 мм при метрологической аттестации. Отверстия были просверлены в подкате на расстоянии 1,5 м от поперечного шва, на расстоянии 5мм от края полосы и на расстоянии 300 мм друг от друга. Было просверлено 15 отверстий (5 отверстий диаметром 0,7 мм (дефекты 1-5), 5 отверстий диаметром 1,0 мм (дефекты 6-10), 5 отверстий диаметром 1,5 мм (дефекты 11-15). Измерения проведены после сварки на непрерывной трубе в линии стана (в динамике при скорости движения трубы в стане 60 м/мин и зазоре между датчиком и поверхностью трубы 3 мм).

Опыт промышленной эксплуатации дефектоскопического комплекса УМД-101МК в ОАО «Магнитогорский металлургический комбинат показал, что МП сохраняет свои технические характеристики при непрерывной работе в течение 2,5-3 лет в условиях повышенной температуры, вибрации и влажности. Установлено также, что чувствительность дефектоскопического комплекса соответствует требованиям ГОСТ 31447 и ГОСТ 20295, а также наивысшим уровням чувствительности стандартов ASTM (E570-91), API 5T, API 5L, DIN 476b и др. 


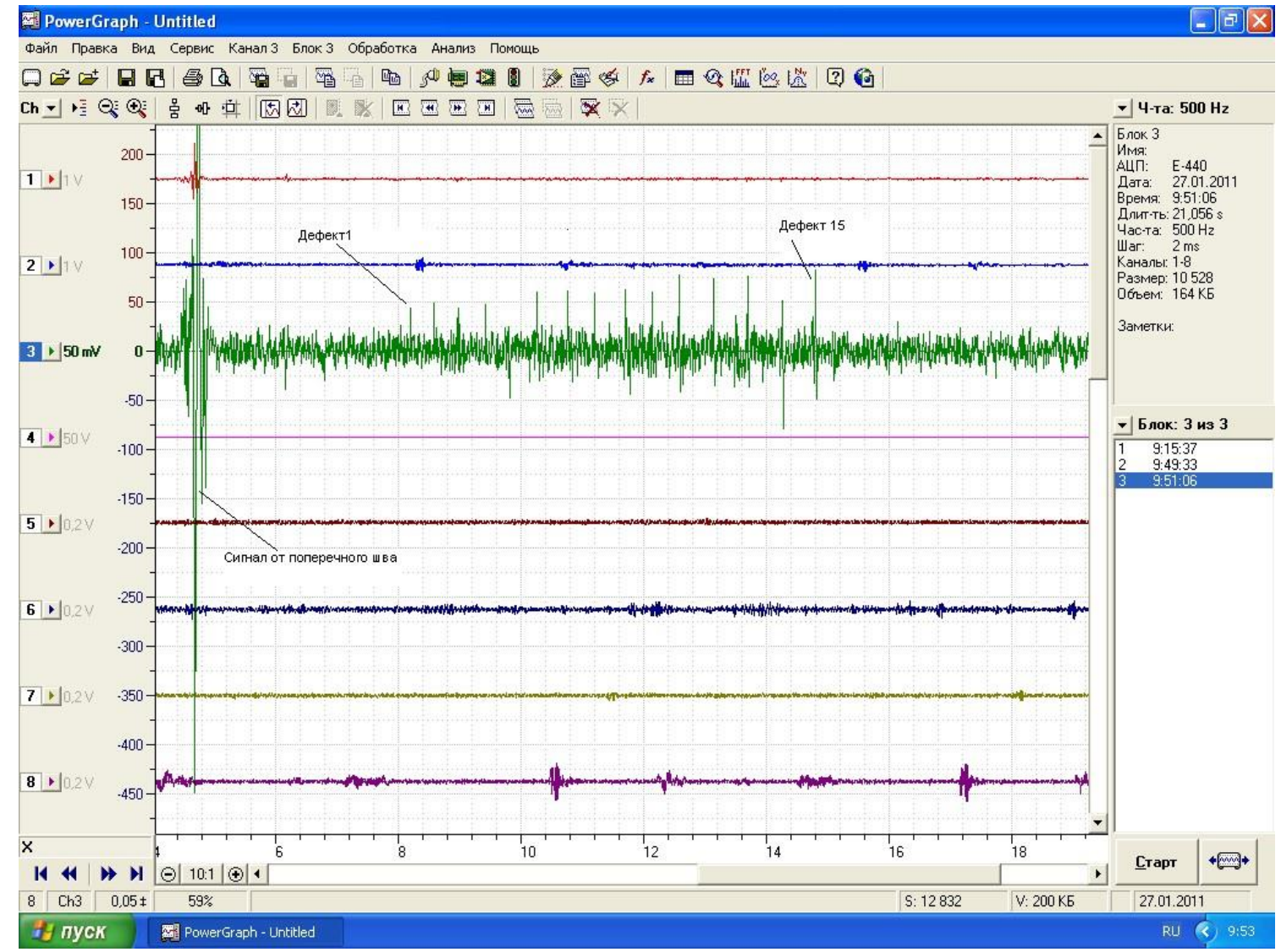

Рис. 2. Сигналы от группы сквозных отверстий

\section{5. Выводы}

1. Установлено, что благодаря высокой чувствительности тонкопленочных матричных преобразователей, изготавливаемых с помощью передовой технологии изготовления датчиков АМРД, предусматривающей высокотемпературный отжиг (до $1200{ }^{\circ} \mathrm{C}$ ) пермаллоевых пленок на окончательной стадии изготовления магниторезистивных датчиков, магнитный контроль труб ведется с рабочим зазором $3 \times 7$ мм. Это не только существенно повышает надежность дефектоскопической аппаратуры, но и позволяет увеличить ее функциональные возможности в плане успешного выявления всех недопустимых дефектов, обусловленных нарушением режимов сварки типа трещин, прижогов и слипаний кромок, а также их смещений в области сварного шва.

2. С целью выбора оптимального соотношения между габаритами и массой НУ и удовлетворением требований по уровню намагничивания было выполнено компьютерное моделирование магнитной системы, на основе результатов которого была разработана конструкция электромагнита, позволившая обеспечить достаточную величину и однородность намагничивающего поля в зоне НК, необходимую для создания одинаковых условий работы МЭ. Благодаря этому удалось существенно уменьшить габариты установки в направлении движения трубы (длина установки вдоль ее оси не более 700 мм), что впервые позволило разместить совмещенный измерительный модуль (магнитный сканер) контрольной позиции дефектоскопического комплекса с системами «верх-низ $180^{\circ} »$, предназначенный одновременно для выявления как продольно ориентированных, так и объемных дефектов в сварном шве и теле электросварных труб по всему периметру и всей толщине стенки (с охватом $360^{\circ}$ ) на общей стационарной платформе между калибровочными клетями. 
3. Предложено для поддержания температурного режима, необходимого для успешной работы МП (датчиков) применять измерительную самоцентрирующуюся кассету на каждый типоразмер (диаметр) контролируемых труб с магниточувствительными элементами-датчиками типа АРМД и прижимным устройством типа пантограф, снабженную тонкостенным металлическим кожухом для водяного охлаждения днища кассеты, а также систему водопитания с фильтром и отстойником, что позволяет значительно расширить температурный диапазон работы датчиков (до $100^{\circ} \mathrm{C}$ );

4. Опыт промышленной эксплуатации дефектоскопического комплекса УМД-101МК в OAO «Магнитогорский металлургический комбинат показал, что его применение обеспечивает возможность контроля нефтегазопроводных труб по всему периметру (и всей толщине стенки) в соответствии с требованиями ГОСТ 31447, ГОСТ 20295, стандартов ISO 10893-3:2011, ASTM (E 570-91) и др., а также возможность выявления как продольных, так и поперечных или/или ориентированных под углом к оси трубу наклонных дефектов.

\section{Благодарность}

Работа выполнена в рамках государственного задания ФАНО России (тема «Диагностика», № AAAA-A18-118020690196-3).

\section{Литература}

1. Пашков Ю. И. Проблемы прочности, разрушения и ресурса труб и трубопроводов. // Тематический сборник научных трудов ОАО «РосНИТИ». - Челябинск, 2001. - С. 58-79.

2. Федосенко Ю. К. Электромагнитный автоматизированный дефектоскопический контроль труб широкой номенклатуры диаметров и марок сталей // Контроль. Диагностика. 2001. - № 5. - C. 25-28.

3. URL: www.kropus.com

4. Shleenkov A. S., Bulychev O. A., Shleenkov S. A. The UMD-101M plant for automated bulk magnetic nondestructive testing of quality of electric-welded pipes // Russian Journal of Nondestructive Testing. - 2008. - Vol. 44. - P. 574-578. - DOI: 10.1134/S106183090808010X.

5. The UMD-104M device for testing reusable oil-well tubing / O. A. Bulychev, S. A. Shleenkov, V. M. Seniv, A. S. Shleenkov, L. A. Polezhaev // Russian Journal of Nondestructive Testing. - 2015. - Vol. 51. - P. 661-668. - DOI: 10.1134/S1061830915110029.

6. URL: www.mac-ndt.com

7. URL: www.foerster.ru

8. URL: www.nov.com/tuboscope

9. URL: www.GEInspectionTechnologies.com

10. Магниторезистивный преобразователь для считывания информации с магнитных носителей : пат. Рос. Федерация / Булычев О.А. - № 2175455 ; заявл. 12.08 .1998 ; опубл. 27.10.2001, Бюл. № 30 .

11. Двухкомпонентный матричный преобразователь магнитного поля : пат. Рос. Федерация / Булычев О. А., Шлеенков А. С. - № 2290654, заявл. 11.25.2004 ; опубл. 27.12.2006, Бюл. № 36.

12. Шлеенков А. С. Разработка матричных преобразователей магнитного поля применительно к неразрушающему контролю ферромагнитных изделий и сварных соединений : дис. ... докт. техн. наук. - Екатеринбург, 1998. -398 с.

13. Estimating the possibility of the magnetic detection of microflaws in weld seams of longitudinal electric-welded pipes manufactured by butt high-frequency welding / A. S. Shleenkov, O. A. Bulychev, N. M. Lyadova, V. E. Shcherbinin, and V. G. Bychkov // Russ. J. Nondestr. Test. 2010. - Vol. 46, no. 2. - P. 92-97. - DOI: 10.1134/S1061830910020038.

14. Булычев О. А., Шлеенков С. А., Шлеенков А.С. Многоканальная магниторезистивная система магнитного контроля бесшовных толстостенных труб // Дефектоскопия. - 2018. № 10. - C. 58-63. 